\title{
Nasal trauma: \\ Primary reconstruction with open rhinoplasty
}

\author{
I Konstantinidis MD PhD, H Malliari MD, S Metaxas MD PhD
}

\author{
I Konstantinidis, H Malliari, S Metaxas. Nasal trauma: Primary \\ reconstruction with open rhinoplasty. Can J Plast Surg \\ 2011;19(3):108-110.
}

Due to the prominent location of the nose, the most common facial traumas are nasal injuries. Although nasal traumas usually require staged intervention at a later period of time, in selected cases, primary reconstruction can be effective. A 20-year-old man who was referred from the emergency department with nasal trauma is presented. He reported a fall after feeling unsteady, which caused a direct nasal injury. Clinical examination revealed septal fracture with obstruction of the left nasal cavity and deformity of the nasal pyramid (inverted $\mathrm{V}$ deformity). The patient also had a complete dissection of the columella skin. Epistaxis was self-limited, and an open rhinoplasty procedure was decided because the trauma occurred $1 \mathrm{~h}$ before admission and there was no significant edema. Surgical intervention included septal reconstruction combined with restoration of the nasal pyramid and columella. One month later, the patient had patent nasal airways, and he was satisfied with the aesthetic result.

Key Words: Inverted V deformity; Nasal reconstruction; Nasal trauma; Open rhinoplasty

\section{Un traumatisme nasal : une reconstruction primaire par rhinoplastie ouverte}

Étant donné la place proéminente du nez, les principaux traumatismes faciaux sont des traumatismes nasaux. Même si, en général, les traumatismes nasaux exigent une intervention échelonnée effectuée ultérieurement, dans certains cas, une reconstruction primaire peut être efficace. Le cas d'un homme de 20 ans aiguillé du département d'urgence en raison d'un traumatisme nasal est présenté. Il avait déclaré être tombé après s'être senti instable, ce qui a provoqué un traumatisme nasal direct. L'examen clinique a révélé une fracture du septum accompagnée d'une obstruction de la cavité nasale gauche et d'une déformation de la pyramide nasale (déformation en $\mathrm{V}$ inversé). Le patient présentait également une dissection complète de la peau de la columelle. L'épistaxis était spontanément résolutive, et il a été entendu de procéder à une rhinoplastie ouverte parce que le traumatisme s'était produit une heure avant l'admission et qu'il ne s'accompagnait pas d'un œdème important. L'intervention chirurgicale incluait une reconstruction du septum associée à une restauration de la pyramide nasale et de la columelle. Un mois plus tard, les voies aériennes du patient étaient dégagées, et il était satisfait du résultat esthétique. injured part of the face $(1,2)$. Even minor nasal traumas may result in significant aesthetic and/or functional defects (2). The current management for the majority of nasal injuries is closed reduction of nasal fractures and, if required, a second operation at a later time. However, the significant percentage of patients needing a septorhinoplasty after primary care raises questions, at least in a few cases, regarding the need for an early intervention (3). Additionally, patients tend to avoid a second operation despite a nonacceptable aesthetic and/or functional result (3). Indications for an early full septorhinoplasty are not clear in the literature. The present case describes a trauma that requires a more sophisticated operation than a simple manipulation of nasal bones. This primary management is often difficult because of the presence of edema (4). However, in some cases, the patient is immediately admitted to the hospital and surgeons have the opportunity to clearly visualize the deformity before swelling occurs. We present a case of an inverted $\mathrm{V}$ deformity caused by nasal injury as an indication for primary reconstruction with an open approach.

\section{CASE PRESENTATION}

A 20-year-old man was admitted to the 2nd Academic ORL Department of Papageorgiou Hospital (Greece) with an acute nasal injury and moderate epistaxis, due to a fall on a rigid metallic surface at his home. The nasal trauma consisted of complete separation of the bony vault from the cartilaginous vault (inverted V deformity), a vertical fracture of the cartilaginous nasal septum with mucosal laceration causing complete obstruction in the left nasal cavity and a skin laceration at the level of the nasal columella (Figures 1A and 1B). The caudal end of the septum was displaced without fracture out of the nasal spine posteriorly. The time interval between injury and assessment was $1 \mathrm{~h}$ and, thus, a

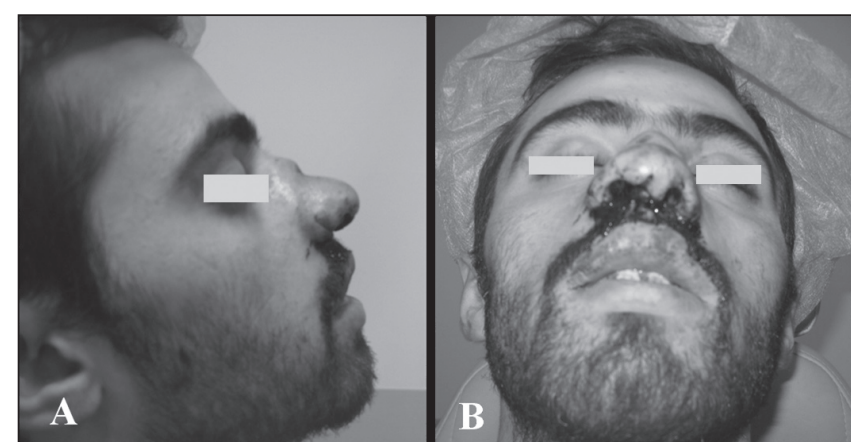

Figure 1) A Front view of the columella injury and the inverted $V$ deformity. B Separation of the osseocartilaginous junction is more obvious in the lateral view

primary surgical reconstruction was decided because there was no significant edema of the nose. The epistaxis was self-limited and did not require any further treatment. Detailed neurological assessment did not reveal any defect.

An open rhinoplasty approach under general anesthesia was performed through the open wound of the columella. After identification of the osseocartilaginous separation, the cartilaginous vault was manipulated with a long nasal speculum to approach the level of the bony vault and secured with three nonabsorbable sutures (white Gore-tex 3.0 [WL Gore \& Associates Inc, USA]) - one in the midline at the level of the nasal septum passing through the bone, and one laterally on each side between the upper lateral and the periosteum of the nasal bones (Figure 2). 
Intercartilaginous sutures were used for the reconstruction of the fracture of the quadrangular septal cartilage posteriorly along with sutures securing the mucosal flaps (Vicryl 4.0, Ethicon, Johnson \& Johnson Medical Limited, UK). The stability of the nasal tip required additional sutures between the medial crura of the lower cartilages and the caudal end of the quadrangular cartilage, along with a suture for the repositioning of the septum on the maxillary crest anteriorly (Figure 2). Finally, after careful removal of the necrotic tissue, skin lacerations were approximated with interrupted nonabsorbable sutures (nylon 6) and the columella was covered without any use of a skin graft. During the operation, no cartilaginous graft was harvested because the open wound trauma had the potential risk of an infection and graft resolution. Nasal packing and silicone splints were placed and remained in the nose for 10 days under antibiotic treatment. External bandaging of the nose was finally undertaken, ensuring excessive pressure was not applied to the columella skin. The patient had an uneventful recovery without complications postoperatively. In a follow-up appointment one month later, the patient had an acceptable aesthetic result with a patent nose on both sides (Figures $3 \mathrm{~A}, 3 \mathrm{~B}$ and $3 \mathrm{C})$. Because the wound healing of the columella was problematic, the patient was counselled to undergo a second operation at a later time if the aesthetic result of the columella skin remained unsatisfactory. However, the patient was satisfied with the result and decided to not undergo any further treatment.

\section{DISCUSSION}

The current management in the majority of nasal injuries worldwide is closed reduction and, if required, a second operation at a later time. However, surgeons may have to reassess their treatment algorithm, and more often adopt an early full septorhinoplasty approach (5). Indications for an early full surgical intervention remain unclear. According to Mondin et al (3), indications for full surgical reduction could be extensive fracture-dislocation of the nasal bones and septum, nasal pyramid deviation exceeding one-half of the width of the nasal bridge, fracture and dislocation of the caudal septum and open septal fracture. In our case, an early open approach was performed due to open traumas at the columella and the quadrangular cartilage, and the separation of cartilaginous vault from the bony pyramid. This is in agreement with other studies $(4,6)$ that suggested an open rhinoplasty when a septal fracture is combined with a nasal pyramid deformity.

The need for earlier septorhinoplasties is based on two facts: the significant incidence of postreduction nasal deformities requiring rhinoplasty or septorhinoplasty, which ranges from $14 \%$ to $50 \%$ $(7-10)$, and the majority of patients who usually elect not to undergo a second operation (11).

Harrison (12) experimentally described a recurring pattern of septal fracture and displacement produced in 15 cadavers, giving evidence for the causes of the poor outcome of a simple manipulation (12). A

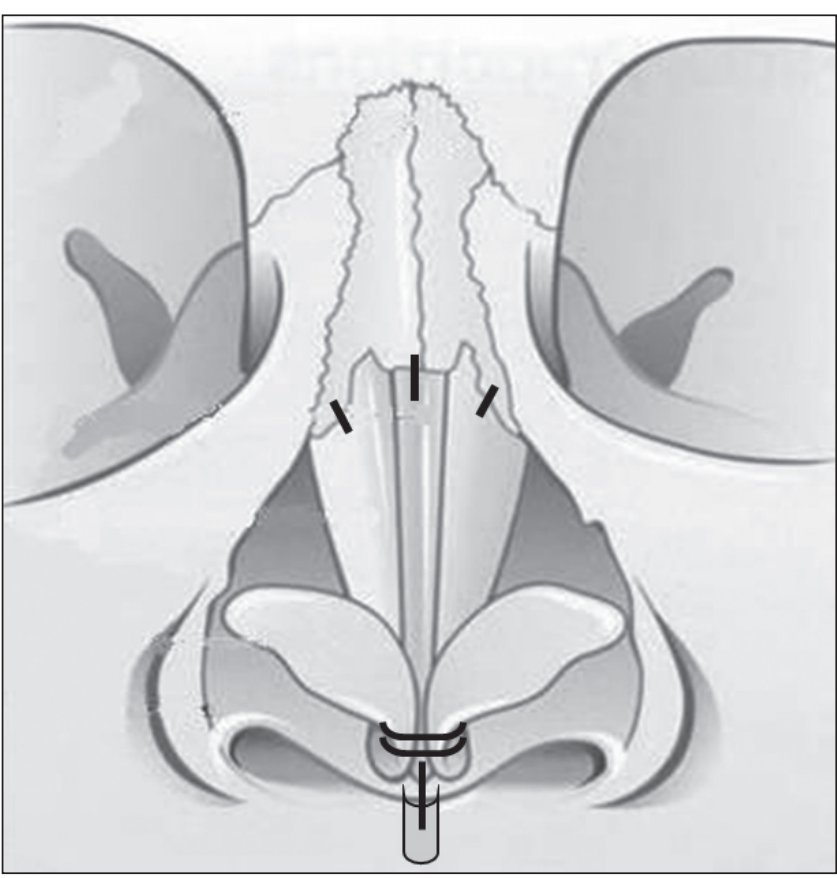

Figure 2) Schematic drawing of the nasal reconstruction with sutures between the osseous and cartilaginous vaults and sutures for strengthening and repositioning of the columella

fractured septum should be considered a significant factor, which can unfavourably affect the alignment of the nasal bone during the healing process (13).

Using septorhinoplasty techniques, the postinitial operation deformity decreased to $11.5 \%$ (5). This is in accordance with the revision rates of septorhinoplasty reported in the literature $(5.3 \%$ to $18 \%)(14)$.

There is evidence that patients are very often pleased with the aesthetic result of their nose while this is not true for the surgeon (15). Watson et al (16) suggested that a patient's fear of a second general anesthetic may contribute to the patient's statement.

Another factor supporting early rhinoplastic procedures is the technical difficulties that surgeons must face regarding revision rhinoplasty for a traumatic nasal deformity $(4,6,13)$. Thus, adequately identifying and optimizing the initial treatment of the nasal complex fractures is key in decreasing the need for secondary surgery.

The limitation for an early septorhinoplasty usually is the time interval between injury and clinical assessment. It has been reported
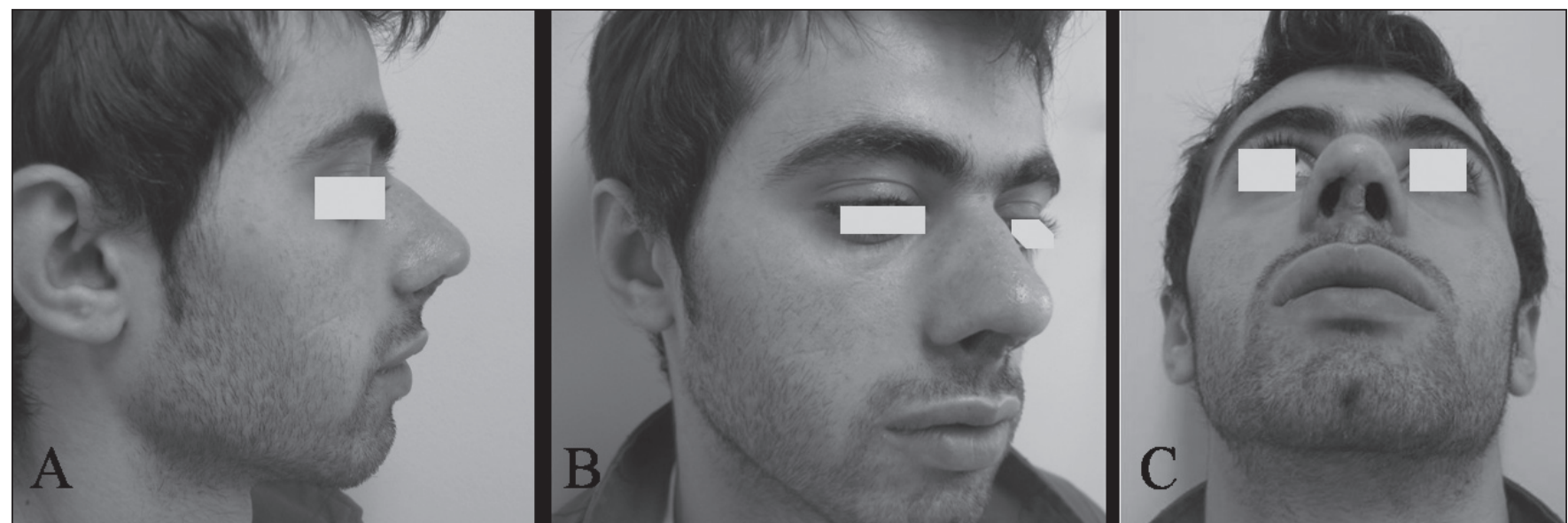

Figure 3) A Postoperative lateral view at one-month follow-up. B Oblique view. C Columella view 
that a $3 \mathrm{~h}$ window postinjury allows optimal evaluation before the development of edema (6). However, if action is not taken within hours, this should be performed after a maximum of 10 days for adults and seven days for children $(1,3)$.

If dealing with nasal skin defects, grafts or flaps should rarely be used, and only be used if they are absolutely necessary in an open trauma wound because the potential risk of infection is significantly increased (12). Columella is a tricky subunit to repair because of the low availability of neighbouring skin (17); in a study by Sherris et al (17), only one of 16 patients with columella defect due to trauma was

\section{REFERENCES}

1. Baring D, Murray C, Singh J, Davidson A, Syed I. Prospective, blinded study of nasal injuries: Comparison of doctor and nurse assessment. J Laryngol Otol 2009;123:1338-42.

2. Higuera S, Lee E, Cole P, Hollier L, Stal S. Nasal trauma and the deviated nose. Plast Reconstr Surg 2007;120:64S-75S.

3. Mondin V, Rinaldo A, Ferlito A. Management of nasal bone fractures. Am J Otolaryngol Head Neck Med Surg 2005;26:181-5.

4. Huizing E, De Groot J, eds. Acute Nasal Trauma in Functional Reconstructive Nasal Surgery. New York: Thieme Publishers, 2003.

5. Fernandes SV. Nasal fractures: The taming of the shrewd. Laryngoscope 2004;114:587-92.

6. Stucker F, de Souza C, Kenyon G, Lian T, Draf W, Schick B, eds. Rhinology and Facial Plastic Surgery. New York: Springer, 2009.

7. Guida R, Rubach B. Aesthetic restoration of acquired nasal defects. Oper Tech Otolaryngol Head Neck Surg 2000;11:102-9.

8. Murray JA, Maran AG, MacKenzie IJ, et al. Open versus closed reduction of the fractured nose. Arch Otolaryngol 1984;110:797.

9. Rubinstein B, Strong EB. Management of nasal fractures. Arch Fam Med 2000;9:738-42. operated with the use of a local flap. In complex wounds, the aesthetic result should be judged at a later time. In cases of unsatisfactory wound healing, a second skin flap or free graft reconstruction can be performed $(7,17)$.

Although an early rhinoplastic procedure does not often seem to be a first-line procedure, in the long term, it is more effective for the patient and the health care system because it avoids a significant number of secondary operations. Rhinoplastic techniques should be part of the training programs in the modern management of severe nasal traumas.

10. Waldron J, Mitchell DB, Ford G. Reduction of fractured nasal bones: Local versus general anaesthesia. Clin Otolaryngol 1989;14:357-9.

11. Staffel JG. Optimizing treatment of nasal fractures. Laryngoscope 2002;112:1709-19.

12. Harrison DH. Nasal injuries: Their pathogenesis and treatment. Br J Plast Surg 1979;32:57-64.

13. Rhee SC, Kim YK, Cha JH, et al. Septal fracture in simple nasal bone fracture. Plast Reconstr Surg 2004;113:45-52.

14. Rohrich RJ, Muzaffar A. Rhinoplasty. In: Romo T III, ed. Aesthetic Facial Plastic Surgery. New York: Thieme Publishers, 2000.

15. Crowther JA, O'Donoghue GM. The broken nose: Does familiarity breed neglect? Ann R Coll Surg 1987;69:259-60.

16. Watson DJ, Parker AJ, Slack RW, et al. Local versus general anaesthetic in the management of the fractured nose. Clin Otolaryngol 1988;13:491-4.

17. Sherris D, Fuerstenberg J, Danahey D, Hilger P. Reconstruction of the nasal columella. Arch Facial Plast Surg 2002;4:42-6. 